\title{
Quality of life is predictive of relapse in schizophrenia
}

\author{
Laurent Boyer $^{1 *}$, Aurelie Millier ${ }^{2}$, Emeline Perthame ${ }^{2}$, Samuel Aballea ${ }^{2}$, Pascal Auquier ${ }^{1}$ and Mondher Toumi ${ }^{3}$
}

\begin{abstract}
Background: The objective of this study was to evaluate whether quality of life (QoL), as measured by the SF36 and the Quality of Life Interview (QoLI), is predictive of relapse for patients with schizophrenia.

Methods: Using data from a multicenter cohort study conducted in France, Germany, and the United-Kingdom (EuroSC), we performed Cox proportional-hazards models to estimate the associations between QoL at baseline and the occurrence of relapse over a 24-month period, with adjustment for age; gender; positive, negative and general psychopathology PANSS factors; functioning (GAF); medication; side-effects; and compliance measures.

Results: Our sample consisted of 1,024 patients; 540 (53\%) had at least one period of relapse, and 484 (47\%) had no relapse. QoL levels were the most important features predicting relapse. We found that a higher level of QoL predicts a lower rate of relapse at 24 months: $H R=0.82(0.74 ; 0.91), p<0.001$ for the SF36-Physical Composite Score; and $H R=0.88(0.81 ; 0.96), p=0.002$ for the SF36-Mental Composite Score. These results were not confirmed using the QoLI: HR $=0.91(0.81 ; 1.01), p=0.083$. To a lesser extent, older age, better functioning, and a higher compliance score also predict a lower rate of relapse at 24 months (HRs from 0.97 to $0.98 ; p<0.05$ ).

Conclusions: QoL, as assessed by the SF36, is an independent predictor of relapse at a 24-month follow-up in schizophrenia. This finding may have implications for future use of the QoL in psychiatry. Moreover, our findings may support the development and monitoring of complementary therapeutic approaches, such as 'recoveryoriented' combined with traditional mental health cares to prevent relapse.
\end{abstract}

Keywords: Schizophrenia, Quality of life, Relapse, Compliance, Functioning, Recovery

\section{Background}

Schizophrenia is a severe and chronic mental illness that is characterized by recurrent relapses [1,2]. Relapse is disabling and distressing for the individual with schizophrenia and is associated with a progressive functional deterioration as well as worsening treatment response and clinical prognosis [3]. Moreover, relapse increases caregiver burden [4] and represents a significant economic burden on families and society $[5,6]$. Because the prevention of relapse is a major challenge in the care of patients with schizophrenia, numerous studies have investigated the value of socio-demographic, clinical, and medication factors in the prediction of relapse [1,2,5,7-9]. However, although these reports have provided a better understanding of factors that influence the course of schizophrenia,

\footnotetext{
* Correspondence: laurent.boyer@ap-hm.fr

'Aix-Marseille Univ, EA 3279 Research Unit, Marseille 13284, France

Full list of author information is available at the end of the article
}

these factors imperfectly predict relapse, and the relapse rate still remains high. Other factors, such as social and environmental factors known to influence the course of schizophrenia [10,11], have received scant attention. A more thorough and comprehensive understanding of these factors is necessary. On the other hand, Quality of Life (QoL), which is defined as a subjective evaluation embedded in a cultural, social, and environmental context [12], has gained increasing acceptance in psychiatric research along with the traditional assessments of clinical outcomes. Recent studies have shown QoL to be an independent prognostic factor associated with clinical outcome in various chronic diseases including oncology, often predicting survival or occurrence of hospitalization [13-17]. However, two studies have shown that QoL scores added relatively little to socio-demographic, clinical, and medication factors in the prediction of relapse in schizophrenia [1,5]. Because the median time to relapse
C Biomed Central

(c) 2013 Boyer et al.; licensee BioMed Central Ltd. This is an Open Access article distributed under the terms of the Creative Commons Attribution License (http://creativecommons.org/licenses/by/2.0), which permits unrestricted use, distribution, and reproduction in any medium, provided the original work is properly cited. 
following a previous remission in schizophrenia has been estimated to occur at the end of the first year $[18,19]$, the relatively short follow-up period of these two studies (6 and 12 months) may have underestimated the rate of relapse. To date, no study has assessed whether QoL provides prognostic information in addition to conventional socio-demographic, clinical, and medication factors for patients with schizophrenia after a sufficient follow-up. The objective of this study was to evaluate whether baseline QoL, as measured by the SF36 and the QoLI, is predictive of relapse for patients with schizophrenia over a 24-month follow-up.

\section{Methods}

\section{Study design and sampling}

The data are from the European Schizophrenia Cohort (EuroSC) conducted in France, Germany, and the United Kingdom (UK). A detailed description of the EuroSC has been published previously [20]. It is a naturalistic 2-year follow-up, from 1998 to 2000, of a cohort of patients suffering from schizophrenia. The study was observational, as no intervention was made either by or at the behest of the research team. The main objective of the EuroSC was to identify and describe the types of treatment and methods of care for individuals with schizophrenia and to correlate these with clinical outcomes, states of health, and quality of life. This study was conducted in accordance with the Declaration of Helsinki and the French Good Clinical Practices. The protocol of this study was approved by the Institutional Review Board or the Ethics Committee responsible for the participating hospital or institution: The Amden \& Islington Community Mental Health NHS Trust Ethics Committee and The Leicester University Committee for Research Ethics for all UK sites, The Ethics Committee of the University of Leipzig for Germany, and The Ethics Committee of the University of Aix-Marseille 2 for France. Written informed consent was obtained from each participant after the study details had been fully explained.

In France, participants were recruited from 4 areas: Lille (Northern France), Lyon, Clermont-Ferrand (Central France), Marseille and Toulon (Southern France). In Germany, the study took place in 4 areas: Leipzig and Altenburg in the former East Germany, and the districts of Hemer and Heilbronn in the former West Germany. In the UK, the two centers of Islington, an inner-city area of London, and the county of Leicestershire (excluding the city of Leicester) were chosen. In each center, patients were identified according to the following criteria: diagnosis of schizophrenia according to the DSM-IV criteria [21], ages 18 to 64 years, and absence of relapse for the previous 12 months. Random sampling from these patients was used to generate a representative sample. The sample included 1,208 patients: 287 from France, 619 from Germany, and 302 from the UK. Five interviews were completed with each participant at initial assessment and after every 6 months for the subsequent 2 years. Sample attrition resulted in $1024(84.8 \%)$ participants taking part in the second interview, $914(75.7 \%)$ in the third, 777 (64.3\%) in the fourth, and 684 (56.7\%) in the final interview.

\section{Data collection}

The following data were collected at baseline:

1. Socio-demographic information: gender, age, living conditions, and employment status.

2. Clinical characteristics: psychotic symptoms based on the Positive and Negative Syndrome Scale (PANSS), which includes three different subscales (positive, negative and general psychopathology) [22]; and functioning based on the Global Assessment of Functioning (GAF) scale [23].

3. Drug information: Antipsychotic medication (first-generation antipsychotics - FGAs, second-generation antipsychotics - SGAs); the Simpson and Angus Scale (SAS) [24], the Barnes Akathisia Scale (BAS) [25], and the Abnormal Involuntary Movement Scale (AIMS) [26] were used to assess side-effects; the Rating of Medication Influences (ROMI) Scale was used to evaluate adherence to treatment [27]. We only examined the responses to Part I of the ROMI, which assesses the reasons for taking the medication. In our analysis, however, we did not include Part 2 of the ROMI, which assesses the reasons why people might not take their medication. According to Weiden et al. [27], the non-compliance items in the ROMI apply only to patients who have not taken their medication for at least one week for any part of the past month; otherwise, only the compliance items are administered. The latter situation applied to all participants in this study.

4. QoL was assessed using 2 types of questionnaires: a generic measure usable regardless the health status of the individual (either healthy or with different health conditions) - the SF36 [28]; and a measurement specific to people with chronic mental illnesses, tailored to a broad range of mental illnesses - the Quality of Life Interview (QoLI) [29].

The SF36 is a generic, self-administered QoL questionnaire consisting of 36 items describing 8 dimensions: Physical Functioning (PF); Social Functioning (SF); RolePhysical Problems (RPP); Role-Emotional Problems (REP); Mental Health (MH); Vitality (VIT); Bodily Pain (BP); and General Health (GH). Two composite scores can be calculated: the physical composite score (SF36PCS) and the mental composite score (SF36-MCS). Each dimension is scored within a range from 0 (low QoL level) to 100 (high QoL level). 
The QoLI is an instrument specifically designed to assess QoL in patients with severe mental illnesses. It consists of 74 items describing 8 domains: Living Situation (LS), Daily Activities and functioning (DA), Family Relationships (FR), Social Relationships (SR), Finances (F), Work and School (WS), Legal and Safety Issues (LSI), and Mental and Physical Health (MPH). Each domain is rated objectively by an interviewer and subjectively by the patient reporting his/her satisfaction through an individual structured interview. Subscale scores and an overall life satisfaction (OLS) score are calculated, ranging from 1 to 7. Higher scores indicate a better QoL.

For the purpose of the study, only the SF36-PCS, SF36-MCS, and QoLI-OLS were included in the analyses.

\section{Study outcomes}

Our primary measure was the time to first relapse during a 24-month period. Relapse was defined according to a common, clinically reproducible and validated definition [30,31]: (1) hospitalization due to worsening of psychotic symptoms or an unequivocal worsening of psychotic symptoms of such magnitude that hospitalization appeared imminent, or (2) a re-emergence of florid psychotic symptoms such as delusions, hallucinations, or bizarre behavior, or (3) a thought disorder lasting seven days or more. This information was obtained by a structured clinical interview, centred on a checklist of criteria, conducted by a psychiatrist every six months. Relapse was defined relative to the baseline characteristics of the patient. Additional relevant information was obtained from medical records and through staff interviews. This process was intended to standardise the collection of information about relapse.

\section{Statistical analysis}

Descriptive statistics, reported as means (SD) or percentages, summarized baseline characteristics by relapse status. Characteristics of patients were compared using Chi-squared or Fisher exact tests for categorical variables and the Student or Wilcoxon rank sum test for continuous variables. Cox proportional hazards models were also used for the univariate analyses to predict the interval time to relapse. Subjects were censored from the survival analysis at the time they discontinued the study, i.e. at the time of last interview.

Multivariate Cox proportional-hazards models were performed to estimate the Hazard Ratio (HR) and its corresponding 95\% confidence interval (CI) for associations between QoL scores and the occurrence of relapse, with adjustment for baseline characteristics, one model including the SF36 questionnaire (SF36 model), and one model including the QoLI (QoLI model). The adjustment variables relevant to the models were selected from the univariate analysis, based on a threshold p-value $\leq 0.20$ (age, positive, negative and general psychopathology PANSS scores, GAF score, medication, side-effects based on the BAS score, compliance ROMI score). An additional variable was included in the models owing to its socio-demographic interest (gender). The proportional hazards assumption was investigated by testing the constancy of the log hazard ratio over time by means of log-minus-log survival plots; according to the test, the proportional hazard assumption was not violated. The statistical significance level was set at $\mathrm{p}<0.05$ in a two-sided test. The SAS statistical package (SAS System for Windows, version 9.1) was used to perform all analyses.

\section{Results}

Of the 1,208 patients in the EuroSC, 184 patients were excluded from the analysis because they did not have any follow-up data (15\%). A total of 1,024 patients (85\%) were then included in the present analysis. There were no statistical differences between the 1,024 patients in the study group and those 184 who were excluded in terms of age, gender, living condition, functioning (GAF score), antipsychotic medication, SAS, BAS AIMS, and QoL scores at baseline (all p-values $>0.05$ ). On the contrary, in comparison to included patients, excluded patients had a slightly higher severity of symptoms (respectively 56.5 (20.2) vs. 64.3 (24.9), $\mathrm{p}=0.001$ for the total PANSS score) and lower compliance scores (respectively 11.0 (3.3) vs. 11.5 (3.1), $\mathrm{p}=0.043$ for the ROMI compliance score).

\section{Baseline characteristics of patients with relapse and no relapse}

The baseline characteristics of the patients with relapse and no relapse are reported in Table 1 . Five hundred and forty patients (53\%) had at least one period of relapse, and 484 (47\%) had no relapse. Patients with relapse were significantly younger than patients with no relapse, but no significant difference was found for gender and living conditions. Patients with relapse also had higher levels of severity (positive, negative, and general psychopathology PANSS factors) and a lower level of functioning. The proportion of patients receiving SGAs was significantly higher in patients with relapse than in patients with no relapse. Side effects as assessed with the AIMS, BAS, and SAS and compliance as assessed with the ROMI did not differ significantly between the two groups. Concerning QoL scores, patients with relapse reported lower QoL levels than patients with no relapse for the SF36-PCS, SF36-MCS, and QoLI-OLS.

\section{Predictors of relapse in the Cox's proportional hazard models}

In the univariate Cox's proportional hazard models analysis (Table 1), relapse was significantly predicted by older age, higher level of severity, lower level of functioning, SGAs, lower compliance and lower QoL level. 
Table 1 Characteristics of the patients according to relapse status and univariate Cox proportional-hazards models: Crude Hazard Ratio (HR) and its corresponding $95 \%$ confidence interval $(95 \% \mathrm{Cl})$

\begin{tabular}{|c|c|c|c|c|c|c|}
\hline & \multicolumn{2}{|c|}{ Relapse } & \multirow[b]{3}{*}{ p-value } & \multirow[b]{3}{*}{ Crude HR } & \multirow[b]{3}{*}{$95 \% \mathrm{Cl}$} & \multirow[b]{3}{*}{ p-value } \\
\hline & Yes $(N=540)$ & No $(N=484)$ & & & & \\
\hline & $M(S D)^{1}$ & $M(S D)$ & & & & \\
\hline \multicolumn{7}{|l|}{ Socio-demographic characteristics } \\
\hline Age & $40.3(10.1)$ & 42. $0(11.6)$ & $p=0.013$ & 0.99 & $(0.98 ; 0.99)$ & $p=0.004$ \\
\hline Gender (Male), N (\%) ${ }^{2}$ & 62.1 & 61.2 & $p=0.773$ & 0.97 & $(0.82 ; 1.16)$ & $p=0.762$ \\
\hline Living alone, $\mathrm{N}(\%)$ & 33.5 & 34.5 & $p=0.740$ & 0.97 & $(0.81 ; 1.16)$ & $p=0.754$ \\
\hline Unemployed, N (\%) & 56.9 & 35.7 & $P=0.240$ & 0.79 & $(0.53 ; 1.15)$ & $p=0.237$ \\
\hline \multicolumn{7}{|l|}{ Severity of symptoms: PANSS $^{3}$} \\
\hline Positive PANSS score & $12.7(5.7)$ & $11.7(5.1)$ & $p=0.003$ & 1.03 & $(1.01 ; 1.04)$ & $p=0.001$ \\
\hline Negative PANSS score & $16.1(7.3)$ & $14.6(7.5)$ & $p=0.002$ & 1.02 & $(1.01 ; 1.03)$ & $p=0.001$ \\
\hline General Psychopathology PANSS score & $29.7(10.2)$ & $27.7(10.1)$ & $P=0.001$ & 1.02 & $(1.01 ; 1.02)$ & $p<0.001$ \\
\hline \multicolumn{7}{|l|}{ Functioning } \\
\hline $\mathrm{GAF}^{4}$ & $48.5(15.6)$ & $55.0(15.9)$ & $p<0.001$ & 0.98 & $(0.98 ; 0.99)$ & $p<0.001$ \\
\hline \multicolumn{7}{|l|}{ Side Effects } \\
\hline $\mathrm{BAS}^{5}$ & $1.3(3.0)$ & $1.1(2.7)$ & $p=0.192$ & 1.02 & $(0.99 ; 1.04)$ & $p=0.147$ \\
\hline $\mathrm{AIMS}^{6}$ & $3.0(6.9)$ & $2.5(5.6)$ & $p=0.228$ & 1.01 & $(0.99 ; 1.02)$ & $p=0.328$ \\
\hline $\mathrm{SAS}^{7}$ & $3.5(8.2)$ & $3.5(7.7)$ & $p=0.963$ & 1.00 & $(0.99 ; 1.011)$ & $p=0.990$ \\
\hline \multicolumn{7}{|l|}{ Medication } \\
\hline Second-generation antipsychotics (Yes), N (\%) & 45.6 & 38.9 & $p=0.034$ & 1.26 & $(1.06 ; 1.49)$ & $p=0.009$ \\
\hline \multicolumn{7}{|l|}{ Attitude towards medication: $\mathrm{ROMI}^{8}$} \\
\hline ROMI compliance score & $10.8(3.5)$ & $11.1(3.1)$ & $p=0.223$ & 0.97 & $(0.95 ; 0.99)$ & $p=0.035$ \\
\hline \multicolumn{7}{|l|}{ Quality of life } \\
\hline SF36 - Physical Composite Score * & $47.2(9.8)$ & $49.1(8.7)$ & $p=0.001$ & 0.83 & $(0.76 ; 0.91)$ & $p<0.001$ \\
\hline SF36 - Mental Composite Score ${ }^{* *}$ & $40.3(11.8)$ & $43.7(11.0)$ & $p<0.001$ & 0.84 & $(0.78 ; 0.91)$ & $p<0.001$ \\
\hline QoLI - OLS score ${ }^{* * *}$ & $4.7(0.9)$ & $4.8(0.8)$ & $p=0.006$ & 0.86 & $(0.78 ; 0.95)$ & $p=0.003$ \\
\hline
\end{tabular}

${ }^{1}$ Mean (Standard Deviation); ${ }^{2}$ Effective (Percentage); ${ }^{3}$ Positive and Negative Syndrome Scale; ${ }^{4}$ Global Assessment Functioning; ${ }^{5}$ Barnes Akathisia score;

${ }^{6}$ Abnormal Involuntary Movement Score; ${ }^{7}$ Simpson-Angus score; ${ }^{8}$ Rating of Medication Influences Scale.

* HR for the SF36 - Physical Composite Score should be interpreted this way, "an increase of 10 points on the Physical Composite Score multiplied by 0.83 the instantaneous risk of relapse at 24 months";

** HR for the SF36 - Mental Composite Score should be interpreted this way, "an increase of 10 points on the Mental Composite Score multiplied by 0.84 the instantaneous risk of relapse at 24 months";

*** HR for the QoLI - OLS score should be interpreted this way, "an increase of 1 point on the QoLI score multiplied by 0.86 the instantaneous risk of relapse at 24 months".

Factors that were independently associated with relapse during the 24 months of follow-up on the basis of the multivariate Cox analyses are reported in Table 2. In the SF36 model, QoL levels were the most important features predicting relapse. A higher level of QoL predicts a lower rate of relapse at 24 months for both the SF36-PCS and -MCS. To a lesser extent, older age, better functioning, and higher compliance score also predict a lower rate of relapse at 24 months. On the contrary, the severity of symptoms and second-generation antipsychotics did not significantly predict relapse. In the QoLI model, only older age and better functioning predict a lower rate of relapse.

\section{Discussion}

Using data from the observational EuroSC cohort, we examined the predictive value of QoL with respect to relapse. Our study examined 1,024 patients with schizophrenia; controlled for important socio-demographic, clinical, and medication factors; and has attempted to overcome the limitations of past studies by using a large sample size and a 24-month follow-up, which enables a more complete analysis of full relapse. The findings provide evidence in support of a relationship between QoL scores and relapse in this patient population.

QoL, as assessed by a generic instrument (SF36), is an independent predictor of relapse in schizophrenia. This finding is consistent with a 12-month follow-up study using the SF36, in which a higher level of QoL predicted a moderately lower rate of relapse at 12 months $(\mathrm{OR}=$ 0.98 for both the Physical and Mental Composite Scores) [1]. Surprisingly, this relationship was not confirmed in our study using the QoLI, which only presented a trend $(\mathrm{p}=0.083)$. Again, this finding is consistent with a 
Table 2 Factors associated with relapse during the $\mathbf{2 4}$ months of follow-up in the multivariate Cox proportionalhazards models: Adjusted Hazard Ratio (HR) and its corresponding $95 \%$ confidence interval $(95 \% \mathrm{Cl})$

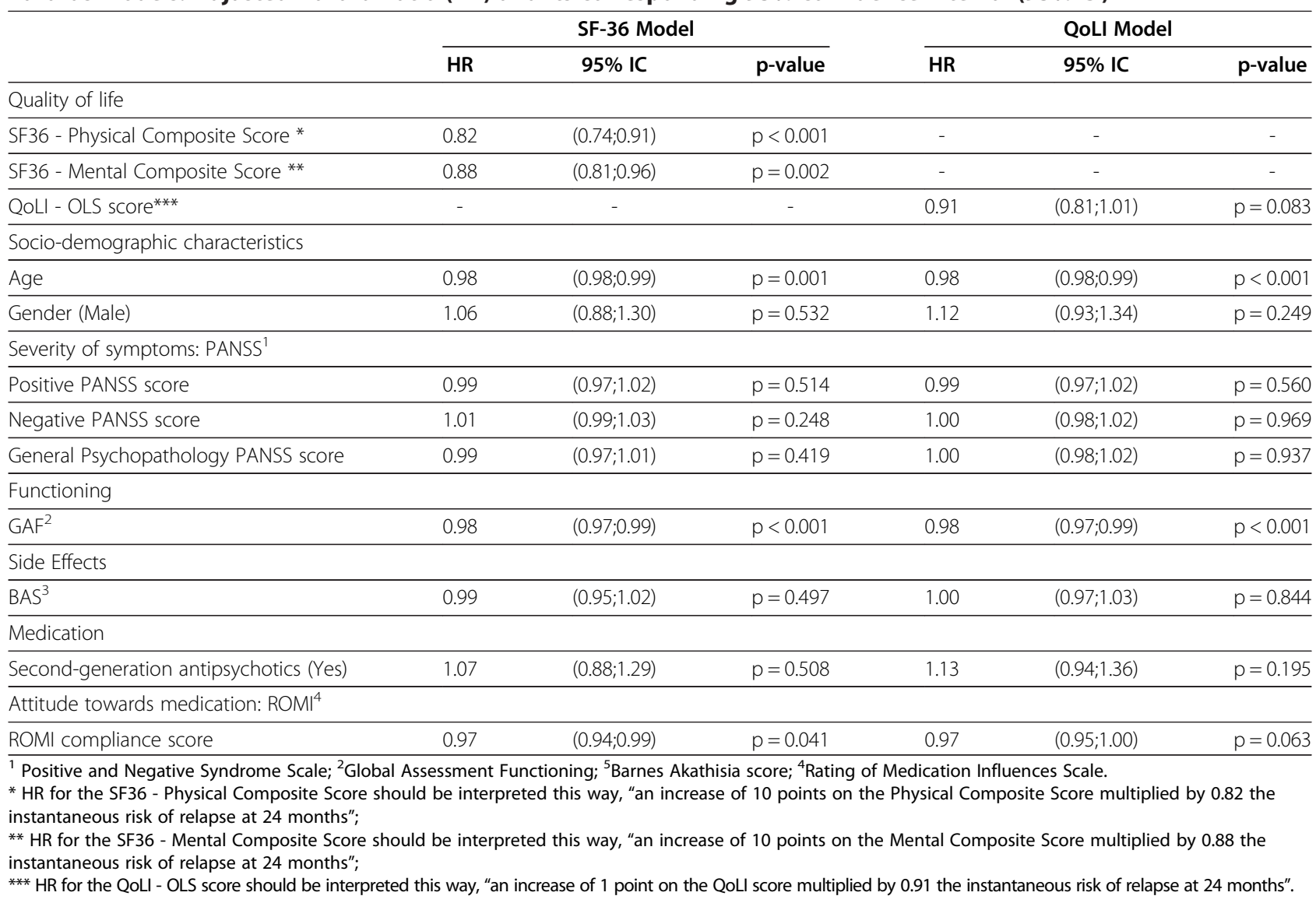

6-month follow-up study using the QoLi, in which relapsed patients appeared to experience a lower QoL than non-relapsed patients at baseline, but the differences were not statistically significant [5]. The fact that a generic instrument like the SF36 better predicts relapse than a specific instrument like QoLI may appear paradoxical. The use of QoL-specific instruments is generally recommended in schizophrenia because they identify the specific needs of patients and are more sensitive to change and treatment/intervention effects than are generic instruments [32]. However, the QoLI is designed to encompass a broad range of mental illnesses, not specifically schizophrenia. According to Cramer et al. [32], the QoLI showed less sensitivity to change and treatment effect than did schizophrenia specific QoL instruments. A previous study has also shown that a better agreement was observed between the SF36 and schizophrenia specific QoL instruments than with the QoLI and that the SF-36 was more strongly correlated with clinical status than the QoLI [33].

An important finding in our study concerns the SF36PCS, which was a stronger relapse predictor compared to the SF36-MCS. This finding confirms the need for clinicians to increase their attention on the physical health of patients with schizophrenia [34]. Although most patients view their physical health as a high priority, many clinicians consider their primary function to be the management of mental and psychological health [35]. The subjective physical well-being of patients with schizophrenia should thus be considered by clinicians as an important predictor of relapse, in the same way that psychological aspects are considered.

In our study, unlike previous studies $[5,7,19,36]$, a more severe symptomatology was not associated with relapse, and other factors such as functioning or compliance were only moderately associated with relapse. One possible explanation for this discrepancy might be that QoL, which was not taken into account as a potential predictor in previous studies, may have a confounding influence on the relationship between traditional predictors and relapse. On the other hand, the exclusion of more severe and less compliant patients (15\% of the cohort) may have also attenuated the predictor strength of symptomatology and compliance. Beyond these explanations, it is interesting to note that, although the predictive value of the different factors was moderate in our study, QoL was a stronger predictor than clinical information. 
Finally, our findings can also be interpreted in terms of the recovery process. The concept of recovery is broadly organised into 2 types: clinical objective (i.e. clinical symptoms and functioning) and personal subjective including in particular QoL among other domains such as personal confidence and hope, willingness to ask for help [37,38]. Our findings suggest that personal subjective recovery (i.e. QoL in our study) is more predictive of relapse than objective recovery. These findings should however be confirmed on other domains of subjective recovery. On the other hand, these results should be considered to improve the characterisation and treatment of patients with schizophrenia. Our findings may support the development and monitoring of complementary therapeutic approaches, such as 'recovery-oriented' combined with traditional mental health cares to prevent relapse. Interestingly, QoL has been linked to metacognitive capacities in recent studies $[39,40]$, suggesting that interventions targeting metacognition, such as psychotherapy, may play a key role in preventing relapse [41].

\section{Limitations}

Some limitations of this study have to be carefully considered.

First, a problem remains with the definition of relapse for schizophrenic patients. There are no consensual criteria for relapse [30]. Admission to a psychiatric hospital unit, increase in medication, worsening of florid symptoms of schizophrenia, worsening of any psychiatric symptoms, and threatened clinical exacerbations have all been variables used to indicate relapse [42]. However, in this study, we have chosen the most commonly used definition in the recent scientific literature.

Second, the representativeness of our sample should be discussed. Although the sampling procedure for the EuroSC aimed to provide a representative sample of the patients treated, this cohort of patients had mostly paranoid schizophrenia and was characterized by long-term illness [20]. Moreover, excluded patients presented with a higher clinical severity than included patients. Replication is therefore needed, using larger and more diverse groups of patients.

Third, $43 \%$ is a moderately high attrition rate in our study at 24 months, and this can lead to biased estimates, especially if patients who did not follow up failed to do so because they suffered a higher relapse rate due to higher clinical severity. However, three facts suggest minimal bias due to attrition. First, among patients lost to follow up, $40.3 \%$ had a relapse before their last visit and were thus included in the analysis. Second, patients lost to follow up did not differ significantly in age, gender, or PANSS scores at baseline from those patients who did follow up ( $\mathrm{p}>0.05$; data not shown). Third, the relapse rate was relatively high (53\%), suggesting that relapses were globally detected. Finally, attrition and relapse rates were globally within the range of other schizophrenia cohorts $[1,5,6,43]$.

Fourth, the SF36 is a generic measure and may not adequately capture all areas of functioning and well-being that are relevant to people with schizophrenia [44]. Moreover, a recent review raised question about metrological properties of the SF36 in schizophrenia [45]. Future investigators should attempt to replicate our findings using disease-specific instruments.

Fifth, compliance is not easy to detect and quantify, and all methods of detection have some drawbacks. As such, the use of the ROMI may be criticised. This scale is a subjective method of assessing compliance in comparison with objective methods such as pill counts, pharmacy records, electronic monitor and plasma concentrations. However, as suggested by Velligan et al., even the use of more objective measures can result in significant errors [46]. Moreover, the ROMI has several advantages. It has good psychometric properties and predicts compliance satisfactorily [27].

Sixth, although our models account for a large set of potentially relevant variables, other factors might have increased their explanatory power. For example, having a history of previous relapse or hospitalisation was not a variable that we examined in our study, although it has previously been identified as an important predictor of relapse [1]. However, in the present study, patients did not have any relapse or hospitalisation for the 12 months prior to the baseline evaluation in accordance with the inclusion criteria. Lastly, despite our large sample, this study only included 3 European countries. Given the important influence of cultural, social, and environmental context on QoL, it would be necessary to know whether our findings can be replicated in other countries.

\section{Conclusion}

This study shows that QoL measures can be considered as an independent predictor of relapse in schizophrenia. This finding may have implications for the future use of QoL in psychiatry. To date, QoL remains largely under-utilized in clinical practice [47]. Several studies have reported that clinicians believe that QoL measures lack clinical relevance for their patients $[48,49]$. More work must be done to convince clinicians of the clinical relevance of QoL instruments in order to enhance the use of QoL measures in clinical decision-making [50]. Our findings, similar to those in other studies, especially in oncology, provide strong support for the integration of QoL into clinical practice along with other standard assessments in psychiatry.

\section{Competing interests}

The authors have declared that there are no conflicts of interest in relation to the subject of this study. 


\section{Authors' contributions}

$L B, A M, P A$ and $M T$ wrote the manuscript. All authors designed the study and wrote the protocol. $L B, A M, E P$, and SA conducted the literature search and analyses. AM and EP conducted the statistical analyses. All authors contributed to and approved the final manuscript.

\section{Acknowledgements}

Our thanks to all of the patients and staff who helped with the study: I Lindenbach, M Swiridoff, F Baehr, G Lauer, T Schwarz, V Becker, J Hoffler, K Siegrist, U Trenckmann, T Brugha, J Smith, D Bagchi, S McCormack, S Wheatley, M Angermeyer, S Bernert, R Kilian, H Matschinger, C Mory, C Roick, M Goudemand, D Beaune, S Dumont, P Bebbington, D Ellis, L Isham, S Johnson, J Pearson, E Perez, A Regan, R White, B Lachaux, P Pasi-Delay, S Declerck, JM Azorin, JP Chabannes, P Chiaroni, I Banovic, K Hansen, C Morin, L Munier, JC Nachef, C Nickel, C Sapin and V Willacy.

\section{Role of funding source}

The study was funded by $\mathrm{H}$ Lundbeck $\mathrm{A} / \mathrm{S}$.

\section{Author details}

'Aix-Marseille Univ, EA 3279 Research Unit, Marseille 13284, France. ${ }^{2}$ Creativ-Ceutical France, rue du Faubourg Saint-Honoré, Paris 75008, France. ${ }^{3}$ Decision Sciences \& Health Policy, Boulevard du 11 Novembre 1918, UCBL 1 - Chair of Market Access University Claude Bernard Lyon I, Villeurbanne 69622, France.

Received: 18 January 2012 Accepted: 4 January 2013

Published: 9 January 2013

\section{References}

1. Ascher-Svanum H, Zhu B, Faries DE, Salkever D, Slade EP, Peng X, Conley RR: The cost of relapse and the predictors of relapse in the treatment of schizophrenia. BMC Psychiatry 2011, 10:2.

2. Robinson D, Woerner MG, Alvir JM, Bilder R, Goldman R, Geisler S, Koreen A, Sheitman B, Chakos M, Mayerhoff D, Lieberman JA: Predictors of relapse following response from a first episode of schizophrenia or schizoaffective disorder. Arch Gen Psychiatry 1999, 56:241-247.

3. Wiersma D, Nienhuis FJ, Slooff CJ, Giel R: Natural course of schizophrenic disorders: a 15-year followup of a Dutch incidence cohort. Schizophr Bull 1998, 24:75-85.

4. Awad AG, Voruganti LN: The burden of schizophrenia on caregivers: a review. Pharmacoeconomics 2008, 26:149-162.

5. Almond S, Knapp M, Francois C, Toumi M, Brugha T: Relapse in schizophrenia: costs, clinical outcomes and quality of life. Br J Psychiatry 2004, 184:346-351.

6. Hong J, Windmeijer F, Novick D, Haro JM, Brown J. The cost of relapse in patients with schizophrenia in the European SOHO (Schizophrenia Outpatient Health Outcomes) study. Prog Neuropsychopharmacol Biol Psychiatry 2009, 33:835-841.

7. Gilmer TP, Dolder CR, Lacro JP, Folsom DP, Lindamer L, Garcia P, Jeste DV: Adherence to treatment with antipsychotic medication and health care costs among Medicaid beneficiaries with schizophrenia. Am J Psychiatry 2004, 161:692-699.

8. Ayuso-Gutierrez JL, Del Rio Vega JM: Factors influencing relapse in the long-term course of schizophrenia. Schizophr Res 1997, 28:199-206.

9. Lipkovich I, Deberdt W, Csernansky JG, Buckley P, Peuskens J, Kollack-Walker S, Zhang Y, Liu-Seifert H, Houston JP: Predictors of risk for relapse in patients with schizophrenia or schizoaffective disorder during olanzapine drug therapy. J Psychiatr Res 2007, 41:305-310

10. Van Os J, Kapur S: Schizophrenia. Lancet 2009, 374:635-645.

11. Allardyce J, Boydell J: Review: the wider social environment and schizophrenia. Schizophr Bull 2006, 32:592-598.

12. Power M, Harper A, Bullinger M: The World Health Organization WHOQOL-100: tests of the universality of Quality of Life in 15 different cultural groups worldwide. Health Psychol 1999, 18:495-505.

13. Kalantar-Zadeh K, Kopple JD, Block G, Humphreys MH: Association among SF36 quality of life measures and nutrition, hospitalization, and mortality in hemodialysis. J Am Soc Nephrol 2001, 12:2797-2806.

14. Parshall MB, Mapel DW, Rice L, Williams A, O'Reilly J: Predictive validity of short-form health survey [36 items] scales for chronic obstructive pulmonary disease exacerbation. Heart Lung 2008, 37:356-365.
15. Sehlen $S$, Lenk M, Hollenhorst $H$, Schymura B, Aydemir U, Herschbach $P$, Duhmke E: Quality of life (QoL) as predictive mediator variable for survival in patients with intracerebral neoplasma during radiotherapy. Onkologie 2003, 26:38-43.

16. Sprenkle MD, Niewoehner DE, Nelson DB, Nichol KL: The Veterans Short Form 36 questionnaire is predictive of mortality and health-care utilization in a population of veterans with a self-reported diagnosis of asthma or COPD. Chest 2004, 126:81-89.

17. Yeo W, Mo FK, Koh J, Chan AT, Leung T, Hui P, Chan L, Tang A, Lee JJ, Mok TS, et al: Quality of life is predictive of survival in patients with unresectable hepatocellular carcinoma. Ann Oncol 2006, 17:1083-1089.

18. Chen EY, Hui CL, Dunn EL, Miao MY, Yeung WS, Wong CK, Chan WF, Tang WN: A prospective 3-year longitudinal study of cognitive predictors of relapse in first-episode schizophrenic patients. Schizophr Res 2005, 77:99-104

19. Weiden PJ, Olfson M: Cost of relapse in schizophrenia. Schizophr Bull 1995, 21:419-429.

20. Bebbington PE, Angermeyer M, Azorin JM, Brugha T, Kilian R, Johnson S, Toumi M, Kornfeld A: The European Schizophrenia Cohort (EuroSC): a naturalistic prognostic and economic study. Soc Psychiatry Psychiatr Epidemiol 2005, 40:707-717.

21. Diagnostic and Statistical Manual of Mental Disorders. 4th edition. Washington, DC: American Psychiatric Association; 1994.

22. Kay SR, Opler LA, Fiszbein A: Significance of positive and negative syndromes in chronic schizophrenia. Br J Psychiatry 1986, 149:439-448.

23. Endicott J, Spitzer RL, Fleiss JL, Cohen J: The global assessment scale. A procedure for measuring overall severity of psychiatric disturbance. Arch Gen Psychiatry 1976, 33:766-771.

24. Simpson S, Angus R: A rating scale for extrapyramidal side effects. Acta Psychiatr Scand Suppl 1970, (212):11-19.

25. Barnes TR: A rating scale for drug-induced akathisia. Br J Psychiatry 1989, 154:672-676.

26. Lane RD, Glazer WM, Hansen TE, Berman WH, Kramer SI: Assessment of tardive dyskinesia using the Abnormal Involuntary Movement Scale. J Nerv Ment Dis 1985, 173:353-357.

27. Weiden P, Rapkin B, Mott T, Zygmunt A, Goldman D, Horvitz-Lennon M, Frances $A$ : Rating of medication influences (ROMI) scale in schizophrenia. Schizophr Bull 1994, 20:297-310.

28. Ware JE Jr, Sherbourne CD: The MOS 36-item short-form health survey (SF-36). I. Conceptual framework and item selection. Med Care 1992, 30:473-483.

29. Lehman AF: A quality of life interview for the chronically mentally ill. Eval Program Plann 1988, 11(1):51-62.

30. Lader M: What is relapse in schizophrenia? Int Clin Psychopharmacol 1995, 9(Suppl 5):5-9.

31. Leucht S, Barnes TR, Kissling W, Engel RR, Correll C, Kane JM: Relapse prevention in schizophrenia with new-generation antipsychotics: a systematic review and exploratory meta-analysis of randomized, controlled trials. Am J Psychiatry 2003, 160:1209-1222.

32. Cramer JA, Rosenheck R, Xu W, Thomas J, Henderson W, Charney DS: Quality of life in schizophrenia: a comparison of instruments. Department of Veterans Affairs Cooperative Study Group on Clozapine in Refractory Schizophrenia. Schizophr Bull 2000, 26:659-666.

33. Reine G, Simeoni MC, Auquier P, Loundou A, Aghababian V, Lancon C: Assessing health-related quality of life in patients suffering from schizophrenia: a comparison of instruments. Eur Psychiatry 2005, 20:510-519.

34. De Hert M, Cohen D, Bobes J, Cetkovich-Bakmas M, Leucht S, Ndetei DM, Newcomer JW, Uwakwe R, Asai I, Moller HJ, et al: Physical illness in patients with severe mental disorders. II. Barriers to care, monitoring and treatment guidelines, plus recommendations at the system and individual level. World Psychiatry 2011, 10:138-151.

35. Millar H: Management of physical health in schizophrenia: a stepping stone to treatment success. Eur Neuropsychopharmacol 2008, 18(Suppl 2):S121-S128

36. Chabungbam G, Avasthi A, Sharan P: Sociodemographic and clinical factors associated with relapse in schizophrenia. Psychiatry Clin Neurosci 2007, 61:587-593.

37. Roe D, Mashiach-Eizenberg M, Lysaker PH: The relation between objective and subjective domains of recovery among persons with schizophreniarelated disorders. Schizophr Res 2011, 131:133-138.

38. Silverstein SM, Bellack AS: A scientific agenda for the concept of recovery as it applies to schizophrenia. Clin Psychol Rev 2008, 28:1108-1124. 
39. Boyer L, Richieri R, Faget C, Padovani R, Vaillant F, Mundler O, Lancon C, Auquier P, Guedj E: Functional involvement of superior temporal sulcus in quality of life of patients with schizophrenia. Psychiatry Res 2012, 202(2):155-160.

40. Lysaker PH, Erickson MA, Buck B, Buck KD, Olesek K, Grant ML, Salvatore G, Popolo R, Dimaggio G: Metacognition and social function in schizophrenia: associations over a period of five months. Cogn Neuropsychiatry 2011, 16:241-255.

41. Lysaker PH, Buck KD, Carcione A, Procacci M, Salvatore G, Nicolò G, Dimaggio G: Addressing metacognitive capacity for self reflection in the psychotherapy for schizophrenia: a conceptual model of the key tasks and processes. Psychol Psychother 2010, Epub ahead of print.

42. Falloon IR: Relapse: a reappraisal of assessment of outcome in schizophrenia. Schizophr Bull 1984, 10:293-299.

43. Caseiro O, Pérez-Iglesias R, Mata I, Martínez-Garcia O, Pelayo-Terán JM, Tabares-Seisdedos R, Ortiz-García de la Foz V, Vázquez-Barquero JL, Crespo-Facorro B: Predicting relapse after a first episode of non-affective psychosis: a three-year follow-up study. J Psychiatr Res 2012, 46(8):1099-1105.

44. Fleischhacker WW, Rabinowitz J, Kemmler G, Eerdekens M, Mehnert A: Perceived functioning, well-being and psychiatric symptoms in patients with stable schizophrenia treated with long-acting risperidone for 1 year. Br J Psychiatry 2005, 187:131-136.

45. Papaioannou D, Brazier J, Parry G: How valid and responsive are generic health status measures, such as EQ-5D and SF-36, in schizophrenia? A systematic review. Value Health 2011, 14:907-920.

46. Velligan DI, Weiden PJ, Sajatovic M, Scott J, Carpenter D, Ross R, Docherty JP: The expert consensus guideline series: adherence problems in patients with serious and persistent mental illness. J Clin Psychiatry 2009, 70(Suppl 4):1-46. quiz 47-48.

47. Awad AG, Voruganti LN: Intervention research in psychosis: issues related to the assessment of quality of life. Schizophr Bull 2000, 26:557-564.

48. Gilbody SM, House AO, Sheldon TA: Psychiatrists in the UK do not use outcomes measures. National survey. Br J Psychiatry 2002, 180:101-103.

49. Greenhalgh J, Long AF, Flynn R: The use of patient reported outcome measures in routine clinical practice: lack of impact or lack of theory? Soc Sci Med 2005, 60:833-843.

50. Boyer $L$, Auquier $P$. The lack of impact of quality-of-life measures in schizophrenia: a shared responsibility? Pharmacoeconomics 2012, 30(6):531-2.

doi:10.1186/1471-244X-13-15

Cite this article as: Boyer et al:: Quality of life is predictive of relapse in schizophrenia. BMC Psychiatry 2013 13:15.

\section{Submit your next manuscript to BioMed Central and take full advantage of:}

- Convenient online submission

- Thorough peer review

- No space constraints or color figure charges

- Immediate publication on acceptance

- Inclusion in PubMed, CAS, Scopus and Google Scholar

- Research which is freely available for redistribution 